\title{
Die reg op godsdiensvryheid in Suid-Afrikaanse skole
}

\author{
I.J. Oosthuizen \\ Nagraadse Skool vir Opvoedkunde \\ Potchefstroomse Universiteit vir $\mathrm{CHO}$ \\ POTCHEFSTROOM \\ E-pos: dopijo@puknet.puk.ac.za
}

\begin{abstract}
The right to religious freedom in South African schools

In general, religion is to be regarded as one of the most important aspects of human life and as one of the key human functions that distinguishes a human being from the rest of creation. For this reason, religious freedom is deemed by many to be the "first liberty" to be protected by any Bill of Rights. However, protecting everyone's religious freedom on an equal and equitable basis is sometimes easier said than done. In the USA, for instance, in an effort to protect the religious rights and freedom of all, a wall of separation between state and religion was implemented on the basis of the US "establishment clause": the American State is compelled to maintain a neutral stance as far as religious matters are concemed. In the eyes of some representatives of the US academe, this approach to the protection of religious freedom ultimately led to the US govemment's becoming the "enemy of religion" in American schools.

In the 1998 case of Wittmann v Deutscher Schulverein, Pretoria the court confirmed that the drafters of the South African constitution steered the issue of religious freedom on a different course to that of the United States. In Wittmann it was held that the South African constitution did not create a wall of separation between church and state (i.c. schools) and that it is the constitutional right of every person (i.c. the learner and the teacher) at school to "entertain such beliefs as a person chooses". The court also held that everyone at school has the right to confess his/her faith and to participate freely in religious worship and religious practice (and even teach and disseminate religion) at school.
\end{abstract}




\section{Inleiding}

Godsdiens word allerweë bestempel as een van die heel belangrikste aspekte van menswees; trouens, dit is een van die eienskappe van die mens wat hom onderskei van die res van die skepping (Venter, 1998:4). Malherbe (1998.673) sê byvoorbeeld dat dit net so deel is van, en onontbeerlik is vir menswees soos asemhaling. Malherbe (1998:692) voer vervolgens die argument verder deur te sê dat, vanweë die persoonlike en sensitiewe aard van godsdiens, dit as 'n belangrike reg beskou moet word - enige beperking daarop kan 'n mens se diepste gevoelens maklik seermaak en selfs tot konflik in die samelewing aanleiding gee. Die rede daarvoor is gelee in die feit dat die mens se godsdiensoortuiging baie diep lê en dit 'n deurslaggewende invloed uitoefen op die mens se optrede (Van der Walt, 1999:63) en uiteindelik ook op sy/haar hele lewensgang. As gevolg hiervan blyk die daarstelling van 'n onbelemmerde ruimte waarbinne die mens se vrye uitlewing van godsdienstige oortuigings moontlik gemaak word, essensieel vir die menslike vreedsame bestaan te wees

Sonder godsdiensverdraagsaamheid is vrede in 'n wêreld van godsdiensverskeidenheid moeilik denkbaar. 'n Oorsig oor die geskiedenis toon aan dat vele konflikte voortspruit uit godsdienstige onverdraagsaamheid tussen onderskeie godsdiensgroepe. Van der Walt (1999:63) noem die volgende voorbeelde van godsdienstige onverdraagsaamheid by die mens

- Onder Christene is daar baie voorbeelde van geweld teen nieChristene en ook van vervolging onderling vanweë die feit dat daar geen ruimte was vir die uitlewing van godsdiens- en gewetensvryheid nie.

- Waar die Islam die bewindhebbers in 'n staat is, bestaan daar 'n geneigdheid om Jode en Christene tot tweederangse burgers te degradeer.

- 'n Breuk met Boeddhisme word deur die nasionalistiese Boeddhis as landsverraad bestempel.

- Waar kommunisme die "staatsreligie" geword het, is die aanhangers van veral die Christelike geloof in Rusland en Oos-Europa met die hoogste graad van hedendaagse godsdiensonverdraagsaamheid vervolg.

Die Amerikaner, Witte (1993:1), maak die stelling dat dit in die moderne wêreld 'n universeel aanvaarde feit is dat godsdiensvryheid die eerste vryheid is wat in enige handves van regte beskerm moet word. Ter 
ondersteuning van dié sienswyse maak hy voorts die volgende opmerking:

Religious liberty was universally accepted as the 'first liberty' to be protected by any Bill of Rights. It is 'the most inalienable and sacred of all human rights' Jefferson put it.

Vorster (1996:12) wat godsdiensvryheid vanuit 'n Christelike perspektief beskou, maak die stelling dat ' $n$ land so regeer moet word dat die kerk die ruimte gelaat word om - as sy primêre taak - die Woord onbelemmerd te kan verkondig. Dit is egter nie net die kerk wat so 'n onbelemmerde ruimte behoort te hê nie: elke Christen het die opdrag ontvang om as individu heen te gaan, die Woord te verkondig om sodoende dissipels te maak.

\section{Begripsverheldering}

Jonker (1993) omskryf die konsep godsdiensvryheid soos volg:

Godsdiensvryheid is 'n fundamentele mensereg of grondreg wat in 'n demokratiese staat gewaarborg moet word. Dit impliseer dat 'n mens die reg het om 'n bepaaide geloof aan te hang of nie aan te hang nie (geloofsvryheid) en om gemeenskappe of kerke te vorm (verenigingsvryheid), om jou geloof in die openbaar te propageer en te beoefen (vryheid van erediens). Dit is tegelykertyd ' $n$ individuele en korporatiewe vryheidsreg. Dit hang ten diepste saam met die erkenning van die vryheid van gewete, wat die wortel van al hierdie vryhede is.

In 1998 het regter Dijkhorst in Wittmann $v$ Deutscher Schulverein, Pretoria die aard van die reg op godsdiensvryheid soos volg omskryf:

[It is] the right to entertain such religious beliefs as a person chooses, the right to declare religious beliefs openly and without fear of hindrance or reprisal, and the right to manifest religious belief by worship and practice or by teaching and dissemination.

Daar word egter 'n duidelike onderskeid getref tussen die konsepte godsdiensvryheid wat godsdiensgelykheid impliseer en godsdiensgelykwaardigheid. Ingevolge artikel 15 van die Suid-Afrikaanse Grondwet het elkeen (ongeag jou geloofsoortuiging of -groepering) die reg op godsdiensvryheid. Dit impliseer gevolglik dat die aanhangers van elke denkbare geloofsoortuiging op 'n gelyke grondslag die reg het om sy/haar geloofsoortuigings vrylik uit te leef en te beoefen. Godsdiensgelykheid is dus 'n juridiese konsep wat impliseer dat die verskillende godsdienste gelyk behandel moet word (Van der Walt, 1999:65). Hoewel alle godsdienste juridies gelyk is, kan dit egter nie, prinsipieel of dogmaties gesproke, gelyk wees in waarde nie (Vorster, 1996:25; Van der Walt, 1999:65). Godsdiensgelykwaardigheid is 'n prinsipieel-dog- 
maties gelaaide konsep: dit het te make met die subjektiewe beginselwaarde wat ' $n$ besondere godsdiens vir die navolgers van daardie godsdiensgroepering inhou. Die owerheid self mag egter nie in subjektiwiteit hom by 'n besondere godsdiensoortuiging skaar nie (Vorster, 1996:25). Samevattend kan daar dus gesê word dat godsdiensvryheid binne die Suid-Afrikaanse grondwetlike bedeling te make het met 'n verpligting wat op die staat gelê word om 'n onpartydige ruimte te skep waarbinne die aanhangers van die verskillende godsdienstige oortuigings op ' $n$ juridies gelyke grondslag die geleentheid gegun moet word om - wat hul onderskeie godsdienste betref - vrylik en ongehinderd te dink, te glo en te waardeer.

In die lig van die voorafgaande beredenerings sal die verskillende kernmomente van die begrip reg op godsdiensvryheid in hierdie artikel verder ontleed word en sal daar ook spesifiek gefokus word op die toepassing van die reg op godsdiensvryheid in Suid-Afrikaanse skole. Daar sal veral vanaf artikel 15 van die Grondwet ordenend te werk gegaan word ten einde die wesensaard van godsdiensvryheid in SuidAfrikaanse skole te ontleed

\section{Die prominensie van godsdiensvryheid in die Suid- Afrikaanse Grondwet}

Die waardes in die Grondwet, soos onder andere gelys in artikels 1 en 7, word in artikel $7(1)$ van die Grondwet as die "hoeksteen van demokrasie in Suid-Afrika" omskryf. Ook moet die waardes ingevolge artikel 39(1) bevorder word by die uitleg van die Handves van Regte. Alhoewel geloof nie as een van die grondwaardes in gemelde artikels gelys word nie, is alle waardes waarskynlik gewortel in een of ander geloof - of die geloof nou 'n uitvloeisel is van die een of ander godsdienstige of niegodsdienstige siening, of nie (Underkuffler-Freud, 1997:50):

Every value or belief implemented by government is presumably a part of some belief system, whether religious or non-religious in nature. To require that all government actions be free of such beliefs is a logical and practical impossibility.

Du Plessis (1996:74) maak die stelling dat die staat se erkenning en veroorlowing van godsdiens en godsdiensbeoefening as 'n grondwetlike imperatief bestempel moet word:

In South Africa the state has a constitutional duty to be for religion. This means that the rights of religious people (and the freedom of religion as such) should enjoy effective protection.

Enkele verdere gronde wat daar ter ondersteuning van só 'n standpuntinname gevind kan word, is soos volg: 
- In die aanhef tot die Grondwet word dié sin as 'n gebed tot God gevind: "Mag God ons mense beskerm". In die volgende reel word die aanhef tot die Grondwet afgesluit met ' $n$ aanhaling van die eerste reel van die Volkslied: "God seen Suid-Afrika". Hoewel die voorrede nie beskou kan word as juridies operasioneel tot die Grondwet nie, dien dit as 'n hulpmiddel by die uitleg van die Grondwet.

- In artikel 9 van die Grondwet word daar eweneens erkenning aan godsdiens gegee waar dit pertinent genoem word as een van die gronde waarvolgens daar nie onbillik gediskrimineer mag word nie. Daar word naamlik bepaal dat daar teen niemand onbillik gediskrimineer mag word op grond van sy of haar godsdiens nie.

- Ingevolge artikel 15 het elkeen 'n reg op vryheid van gewete, godsdiens, denke, oortuiging en mening. Daar word ook bepaal dat godsdiens onder sekere voorwaardes in staats- en staatsondersteunde instellings beoefen mag word.

- Die reg op vryheid van uitdrukking soos opgeteken in artikel 16 van die Grondwet impliseer onder andere dat 'n persoon sy oortuigings as Christen mag bely en dit ook mag verkondig. In verwysing na die hofsaak Kokkinakis $v$ Greece (1994) 17 EHRR 397 wat voor die Europese Hof vir Menseregte gedien het, is 'n Griekse wet wat proselietmakery verbied het, ongeldig verklaar. Malherbe (1998:680) maak op grond van dié hofbevinding - en in die lig van die huidige artikel 16 van die Grondwet - die volgende stelling:

Let daarop dat die openbare uitlewing van godsdiens dus insluit om teenoor ander te getuig en hulle tot dieselfde geloof te probeer oorhaal. Godsdienstige oortuigings kan met ander woorde gemanifesteer word.

- Benewens die individuele element van godsdiensvryheid bestaan daar ook 'n baie duidelike kollektiewe element. Die individuele en kollektiewe elemente van godsdiensvryheid word soos volg in Artikel 18 van die Universele Deklarasie van Menseregte (1948) weerspieël:

Everyone has the right to freedom of thought, conscience and religion or belief, and freedom, either alone or in community with others and in public or private, to manifest his religion or belief in teaching, practice, worship and observance.

Ingevolge artikel 18 van die Grondwet het elkeen die reg om vrylik te assosieer. Die toepassing daarvan binne die konteks van godsdiensvryheid is dat elkeen die reg het om met daardie groep persone met wie hy/sy, volgens eie keuse vrylik wil assosieer, op 'n kollektiewe grondslag sy/haar godsdiens te beoefen. Die kollektiwiteit van godsdiensvryheid 
kan (in die lig van artikel 31) nog een stap verder gevoer word deur formele godsdiensorganisasies soos verenigings, assosiasies en kerke te stig. Ingevolge artikel 31 het die lede van 'n godsdienstige gemeenskap naamlik die reg om saam met ander persone hul gemeenskaplike godsdiensvryheid te beoefen; om godsdiensverenigings en -genootskappe (soos kerke) te vorm, in stand te hou en daarby aan te sluit. Malherbe (1998:679) stel dit soos volg:

Artikel 31 kan onder andere beskou word as 'n grondwetlike erkenning van kerkgenootskappe en ander godsdienstige bewegings se bestaan en rol in die samelewing en sal waarskynlik swaar op gesteun word indien beperkings op daardie rol geplaas sou word.

Die verband tussen 'n persoon se godsdiensvryheid en sy reg op vryheid van assosiasie is dus baie sterk (Malherbe, 1998:680). Organisasies en kerklike groeperings het die reg om te vergader, te organiseer, te aanbid en op te tree ingevolge die tradisies, godsdienstige reels en gebruike wat in ooreenstemming is met die oortuigings (en godsdiens) van hul lidmate (Witte, 1993:23).

- Ingevolge artikels 185 en 186 word voorsiening gemaak vir die instelling van ' $n$ Kommissie vir die Bevordering en die Beskerming van die Regte van Kultuur-, Godsdiens- en Taalgemeenskappe. Hiervolgens moet enkele van die hoofoogmerke van sodanige Kommissie wees om onder andere die respek vir godsdiensregte te bevorder en om vrede, vriendskap, verdraagsaamheid, menslikheid en eenheid onder die godsdiensgemeenskappe te bevorder op 'n grondslag van gelykheid en vrye assosiasie.

Uit die voorafgaande blyk dit ook duidelik dat die reg op godsdiensvryheid ten nouste verweef is met ander grondwetlike regte soos die reg op gelykheid, die reg op vryheid van assosiasie en ook die reg op vryheid van uitdrukking

\section{Godsdiensvryheid as 'n negatiewe en 'n positiewe reg}

Godsdiensvryheid in Suid-Afrika word deur Sizani (1993:11) om die volgende redes as 'n negatiewe reg getipeer:

- Die reg op godsdiensvryheid belet die staat om enigiets te doen om die vrye uitlewing en/of beoefening van godsdiens te verhinder (Vorster, 1996:11).

- Dit lê nie 'n verpligting op die staat om enigiets te doen om dit te bevorder nie - dit kan byvoorbeeld nie van die staat verwag word om 
kerke te bou, godsdienstige literatuur te druk en te versprei, of om godsdiensskole te bou nie.

Volgens Malherbe (1998:681) weer, word daar tog positiewe verpligtinge op die staat geplaas om:

- in 'n gesindheid van onpartydigheid hom te weerhou van die bevoordeling van die een godsdiens bo die ander;

- byvoorbeeld ingevolge artikel 15(2) reels en regulasies daar te stel waarvolgens godsdiensbeoefening in staats- en staatsondersteunde instellings mag plaasvind;

- in ooreenstemming met die Duitse benadering 'n vrye ruimte te skep waarbinne mense hulle oortuigings kan uitleef.

\section{Die onpartydigheid van die staat}

Die "establishment clause" in artikel 1 van die Amerikaanse Grondwet het daartoe aanleiding gegee dat "n skeidsmuur" tussen staat en kerk opgerig is. Die grootste leemte in hierdie benadering lê daarin opgesluit dat die "oordrewe" neutraliteit van die staat daartoe aanleiding gegee het dat dié neutraliteit met verloop van tyd verander het tot 'n staat van vyandigheid jeens godsdiens. In die Amerikaanse hofsaak van 1985, Aguilar $v$ Felton 473 US 402, het die bekende regter Burger hom soos volg oor hierdie kwessie uitsgespreek:

Rather than showing the neutrality the Courts boast of, it exhibits nothing less than hostility toward religion and the children who attend church-sponsored schools

In Everson v Board of Education 330 US 1 (1947) is daar beslis dat, teen die agtergrond van die eerste en veertiende amendemente van die VSA Konstitusie, die skeiding tussen die staat en kerk van so ' $n$ aard is dat godsdiensbeoefening in ' $n$ staatsinstelling nie toelaatbaar is nie. Hierdie Amerikaanse standpunt is soos volg verwoord in Everson $v$ Board of Education:

Neither a state nor the federal government can set up a church. Neither can pass laws which aid one religion, aid all religions, or prefer one religion above another... Neither a state or the federal government can, openly or secretly, participate in the affairs of any religious organisations or groups and vice versa. In the words of Jefferson, the clause against establishment of religion by law was intended to erect 'a wall of separation between church and state'. 
Die reg op godsdiensvryheid in Suid-Afrikaanse skole

Dit het 'n reeks hofsake tot gevolg gehad waarin daar later selfs beslis is dat om 'n gebed te doen by Amerikaanse skole ongrondwetlik is (Smith, 1997:219)

Die probleem van 'n rigiede neutraliteit van die staat het in die VSA tot die "neutrality dilemma" aanleiding gegee. Die Amerikaanse skrywer Valente (soos aangehaal deur Malherbe, 1990:690) skryf hieroor dat, vanuit 'n sekere hoek beskou, dié dilemma daarop neerkom dat leerders beskerm moet word teen onderrig vanuit 'n godsienstige perspektief, maar nie teen onderrig wat indruis teen godsdienstige oortuigings nie:

The neutrality dilemma: protecting students against instruction that favours religious belief, but not against instruction that offends religious belief.

In 'n minderheidsuitspraak in $S \vee$ Lawrence 1997(4) SA 1176(CC) het regter O'Regan (met verwysing na artikel 14 van die Oorgangsgrondwet) soos volg bevestig dat die Suid-Afrikaanse Grondwet nie 'n "establishment clause" bevat soos wat dit die geval met die Amerikaanse Grondwet is nie:

Our Constitution deals with issues differently to the United States Constitution. Section 14 [artikel 15 van die finale Grondwet - IJO] does not include an 'establishment clause' and in my view we ought not to read into it provisions or principles pertaining to the advancement or inhibition of religion by the state.

'n Uitleg van onder andere artikel 14 (artikel 15 van die nuwe Grondwet) dui volgens die regter op 'n neutraliteit van owerheidsweë wat onder andere impliseer dat die staat nie die een godsdiens op 'n direkte of op 'n indirekte manier bokant ' $n$ ander godsdiens mag bevoordeel nie.

Regter O'Regan het in die Lawrence-saak die situasie goed opgesom toe sy 'n fyn onderskeid tussen die begrippe (rigiede) neutraliteit en onpartydigheid getref het. Hiervolgens het 'n mens in die Amerikaanse opset (as gevolg van die invloed van die "establishment clause") te make met (rigiede) neutraliteit. In die Suid-Afrikaanse situasie waar daar nie 'n "establishment clause" ter sprake is nie, het 'n mens eerder met onpartydigheid van owerheidsweë te make. Jonker (1993) verwoord dit soos volg:

En hoewel daar (soos in die Amerikaanse geval) gepraat word van 'n skeiding van staat en kerk, is dit, veral in die Suid-Afrikaanse konteks, meer korrek om van 'n onderskeiding van staat en kerk te praat. Die rede hiervoor is gegrond in die praktyk wat bewys het dat daar 'baie aanrakingsvlakke tussen die twee groothede is' wat dit noop tot 'n bepaalde onderlinge verstandhouding. 


\section{Die reg op godsdiensvryheid}

Artikel 15(1) maak voorsiening vir 'n baie breë spektrum van sienings en geloofsuitings. Benewens die begrip godsdiens word daar ook nog 'n hele aantal ander begrippe opgenoem, te wete: gewete, denke, oortuiging en mening.

Dit is nie eers 'n maklike taak om die betekenis van die begrip godsdiens te omskryf nie (Labuschagne, 1997:118) - en dieselfde geld ook vir elkeen van die ander begrippe. In die Amerikaanse saak, Wisconsin $v$ Yoder (1972) is daar onder andere aangevoer dat filosofiese geloof onderskei moet word van godsdienstige geloof en dat beskerming (in Amerika) net aan laasgenoemde verskaf word. In United States $v$ Seeger-saak (1965) is godsdienstige geloof byvoorbeeld deur die Amerikaanse hof omskryf as 'n geloof wat vir die godsdienstige so ernstig en betekenisvol is, dat dit 'n plek vul wat gelykstaande is aan die ruimte wat deur God gevul word

The court has stated that religious beliefs are those that are sincere and meaningful and occupy in the life of [their] possessor[s] a place paralle to that filled by God.

Met betrekking tot die begrippe gewete, denke en oortuiging sal 'n mens moet wag dat die Suid-Afrikaanse howe in die toekoms die fyner betekenisnuanses daarvan inkleur. Die volgende (voorlopige?) betekenisinhoud is deur skrywers daaraan toegeken (De Waal et al., 1999: 278)

- Gewete moet as 'n breë begrip vertolk word wat rasionalisme en vryheid van denke insluit en wat losstaande is van 'n goddelikheid en wat as gevolg daarvan in die algemene omgangstaal nie gesien word as 'n godsdiens nie. Morele oordeel kan ook as deel van die betekenisinhoud van die begrip gesien word. Rautenbach en Malherbe (1996:331) maak die stelling dat die begrip gewetensvryheid oor die algemeen oorvleuel met vryheid van geloof en godsdiensbeoefening. Jonker (1993:321) is van mening dat die vryheid van die mens as individuele persoon of in korporatiewe verband in die gewete gewortel staan en dat dit ten diepste verband hou met die erkenning van die vryheid van gewete "wat die wortel van al hierdie vryhede is".

In die praktyk is die begrip ter sprake in 'n situasie waar daar 'n innerlike konflik (en worsteling) by 'n persoon ontstaan omdat daar van owerheidsweë 'n optrede (of 'n versuim om op te tree) van hom/haar verwag word en waarvoor hy, vanweë sy diepste persoonlike oortuigings, nie kans sien nie. 
Die reg op godsdiensuryheid in Suid-Afrikaanse skole

- Denke sluit nie morele oordeel in nie en impliseer bloot die beoefening van die menslike rede of denkvermoë.

- Agnostisisme en ateisme word beskou as inbegrepe by sowel die begrippe geloof as gewete.

\section{Godsdiensbeoefening}

Benewens die reg wat elkeen ingevolge artikel 15(1) het op vryheid van gewete, godsdiens, denke, oortuiging en mening, kan godsdiensbeoefening ingevolge artikel $15(2)$ by staats- en staatsondersteunde instellings geskied. Hiervolgens word daar dus ruim voorsiening gemaak vir godsdiensbeoefening in die vorm van byvoorbeeld 'n preek, 'n geestelike boodskap of 'n gebed by 'n skool.

In 1998, in Wittmann v Deutscher Schulverein, Pretoria word die begrip godsdiensbeoefening as ' $n$ handeling van godsdienstige aard, 'n rite, omskryf. Dit moet godsdienstig van aard wees in dié sin dat dit 'n menslike erkenning is van die bonatuurlike beheersende krag van God of gode wat die mens noop tot aanbidding en gehoorsaamheid.

Die hof het ook in die onderhawige uitspraak 'n onderskeid getref tussen godsdiensbeoefening en godsdiensonderrig (bv. Bybelonderrig) en beklemtoon dat artikel 15(2) van die Grondwet nie op godsdiensonderrig by ' $n$ openbare skool van toepassing gemaak kan word nie. Die implikasie hiervan is die bestudering van die Bybel nie verbied word nie: "A Bible period is not forbidden and neither is the study of the Koran".

Regter Dijkhorst voeg ook by dat sodanige godsdiensonderrig in die lig van elkeen se reg op vryheid van gewete, godsdiens, denke, oortuiging en mening nie afgedwing kan word nie en dat dit op 'n vrywilligheidsgrondslag bygewoon moet word

Dit val op dat 'n frase wat in artikel 14(2) van die Oorgangsgrondwet voorgekom het, ontbreek in die ooreenstemmende artikel (15(2)) van die finale Grondwet. Dié frase wat nie weer in die teks van die finale Grondwet opgeneem is nie, is: "14(2) Sonder om afbreuk te doen aan die algemeenheid van subartikel 1". Chaskalson et al. (1999:19-10) is van mening dat die rede hiervoor geleë is in die feit dat die skrywers van die finale Grondwet daarop ingestel was om te verhoed dat daar so 'n sterk skeiding tussen staat en kerk ontwikkel soos wat dit in Amerika die geval is. Smith (1997:220) is byvoorbeeld die mening toegedaan dat die Grondwetskrywers nie wou hê dat die Amerikaanse weg gevolg moet word met die hantering van gebede by skole nie en dat die Duitse voorbeeld eerder nagevolg is waarvolgens gebed by skole deel uitmaak 
van die konsep van vryheid van geloof - op voorwaarde dat sodanige gebed (vir onderwysers en leerders) op 'n vrywillige basis geskied.

\subsection{Staat en staatsondersteunde instellings}

Die invoeging van die frase ("Godsdiensbeoefening kan by ' $n$ staats- of staatsondersteunde instelling geskied ...") in artikel 15(2) was waarskynlik gemik op godsdiensbeoefening in openbare skole (De Waal et al., 1999:290).

'n Ruim uitleg van die frase impliseer dat daar nie net na suiwer staatsinstellings verwys word nie, maar selfs ook na privaatinstellings wat op een of ander wyse ondersteuning van die staat ontvang. Die vorm wat diè ondersteuning by privaatinstellings kan aanneem, kan byvoorbeeld by wyse van finansiële subsidie of selfs belastingtoegewings geskied. Indien hierdie (ruim) wyse van uitleg gevolg word, sou dit dus impliseer dat privaatskole wat subsidie van die staat ontvang, ook ingesluit word by die frase.

Die hof het egter in die Wittmann-saak 'n veel nouer interpretasie aan die konsep staatsondersteun verleen. Die staatsondersteunde inrigting is aan die een kant nie 'n openbare inrigting (i.c. 'n openbare skool) wat deur die staat befonds en beheer word nie, maar dit is aan die ander kant ook nie ' $n$ privaatinstelling nie. In ooreenstemming met die nouer interpretasie wat in die onderhawige hofsaak gevolg is, is die besondere skool as ' $n$ privaat-instelling geklassifiseer - nieteenstaande die feit dat dit (op daardie stadium) ' $n$ jaarlikse subsidie van R1 miljoen van die staat ontvang het. Teoreties bevind die staatsondersteunde inrigting hom dus min of meer in die helfte van 'n kontinuum: die een punt van die kontinuum verteenwoordig daardie instelling wat volledig deur die staat finansieel gesteun en gereguleer word, terwyl die ander punt daardie instelling verteenwoordig wat slegs in ' $n$ geringe mate (en teoreties glad nie) finansieel deur die staat gesubsidieer en gereguleer word nie.

Dit blyk dus ' $n$ redelike veilige standpunt te wees om aan te neem dat artikel 15(2) betrekking het op daardie skole wat in die algemene omgang en in parlementêre wetgewing as openbare skole bekend staan.

\subsection{Besondere beperkingsbepalings}

Die reg op godsdiensbeoefening in staats- en staatsondersteunde instellings is onderworpe aan die besondere beperkingsbepalings soos gelys in artikel 15(2)(a)-(c). Hierdie besondere beperkings vereis dat sodanige godsdiensbeoefening: 
- plaasvind ingevolge die reels wat deur die tersaaklike openbare gesag gemaak is;

- op 'n billike grondslag geskied; en

- op 'n vry en vrywillige basis bygewoon word.

\subsubsection{Wat impliseer openbare gesag?}

Die openbare gesag wat hier ter sprake is, verwys uiteraard na daardie owerheidsorgaan wat in 'n bepaalde geval gesag uitoefen. Byvoorbeeld, in die geval van die onderwys kan dit die provinsiale LUR belas met onderwys wees. 'n Vraag wat ontstaan is: kan die beheerliggaam van ' $n$ skool ook bestempel word as "tersaaklike openbare gesag"? Ingevolge artikel 16(1) van die Suid-Afrikaanse Skolewet (84 van 1996) "setel die beheer van elke openbare skool in sy bestuursliggaam".

\subsubsection{Vry en vrywillig}

Die deelname aan godsdiensbeoefening by 'n staats- of staatsondersteunde instelling (i.c. 'n openbare skool) moet opsioneel wees en mag nie onder dwang geskied nie. Die vraag ontstaan nou wanneer die deelname aan byvoorbeeld gesamentlike gebed vrywillig is, en wanneer daar sprake is van subtiele vorms van dwanguitoefening. Chaskalson et al. (1999:19-10) spreek in dié verband 'n mening uit dat subtiele vorms van dwanguitoefening of indirekte dwang wat op 'n persoon (persone) uitgeoefen word om aan sodanige godsdiensbeoefening deel te neem, nie as vrywillig bestempel kan word nie. As voorbeeld van subtiele dwang stel Chaskalson et al. (1999:19-10) die voorbeeld waar daar in die geval van 'n openbare skool nie 'n aanvaarbare alternatief geskep word vir daardie leerders wat nie aan die gesamentlike godsdiensbeoefening wil deelneem nie. Dié skrywers noem byvoorbeeld dat die plasing van daardie leerders (wat nie aan die godsdiensbyeenkoms wil deelneem nie) in ' $n$ klaskamer om onder die toesig van 'n onderwyser in ledigheid die tyd te verwyl, nie as 'n geskikte alternatief beskou kan word nie - dit sal volgens hom ' $n$ subtiele vorm van dwanguitoefening impliseer. ' $n$ Verdere voorbeeld van subtiele dwang wat die skrywers noem is dat - in die geval van Suid-Afrika, waar die meerderheid mense (i.c. leerders) godsdiensgerig is - dit moontlik is dat die minderheid, wat nie deelneem aan godsdiensbeoefening nie, maklik deur die meerderheid geisoleer en gebrandmerk kan word. Sodanige isolasie kan in sekere gevalle moontlik as ' $n$ subtiele vorm van dwang bestempel word. Chaskelson et al. (1999:19-11) stel dit soos volg: "Religious observances cannot be voluntary if the school in any way disapproves of those who avoid them". 


\subsection{3 'n Billike grondslag}

Die rasionaal vir hierdie frase is met die eerste oogopslag geleë in die beskerming van minderheidsregte. Die meerdersheidsgroep van 'n bepaalde godsdiensoortuiging moet naamlik nie toegelaat word om 'n minderheidsgroep van ' $n$ ander godsdiensoortuiging so te verdring dat laasgenoemde nie die geleentheid gegun word om hul godsdiens (oortuiginge) in 'n skool vrylik uit te leef nie.

Daar is nog baie vrae wat in die toekoms hieroor beantwoord sal moet word. Dit lyk egter nie asof daarmee bedoel word dat - ten einde niemand aanstoot te gee nie - dit van 'n mens verwag word om 'n neutrale gebed te bid waarin die naam van 'n spesifieke god soos Jesus Christus weggelaat word nie. So 'n neutrale gebed is op sigself diskriminerend teenoor die verteenwoordigers van 'n dogmaties spesifieke godsdiens (Smith, 1997:221)

Veel eerder word daar waarskynlik met billike grondslag bedoel dat verwys word na aspekte soos 'n eweredige verspreiding van godsdiensbeoefeningsgeleenthede waarby inbegrepe is 'n eweredige verdeling van tyd en ruimte. Een van die maniere wat volgens Chaskalson et al. (1999: 19-10) kan bydra tot billikheid is om godsdiensleiers in die gemeenskap (soos byvoorbeeld predikante en priesters) wat verteenwoordigend is van die gelowe in die skool te gebruik om godsdiensbeoefeningsgeleenthede by die skool te kom waarneem. By sodanige geleenthede sal so 'n leier dan die leiding neem in die godsdiensbeoefening van die besondere groep wat hy/sy verteenwoordig

\subsection{Privaatskole}

'n Toepassing van artikel 15(2) van die Grondwet op 'n privaatskool (waarvan die onderhawige Duitse privaatskool 'n voorbeeld is) het gevolglik die interessante implikasie dat die besondere beperkings soos gelys in artikels $15(2)(a)$, (b) en (c) nie op privaatskole van toepassing is nie. Dit impliseer gevolglik dat godsdiensbeoefening wel verpligtend vir almal gemaak kan word by 'n privaatskool. Bowendien verleen die reg tot vryheid van assosiasie (artikel 18 van die Grondwet) aan die lede van so 'n assosiasie (i.c. die onderwysdeelnemendes by 'n privaatskool) die reg om van diegene wat deel word van die assosiasie (i.c. privaatskool) te verwag om die reels en beginsels van sodanige assosiasie na te kom Dit het, volgens regter Dijkstra, selfs die implikasie dat niekonformiste deur sodanige assosiasie (i.c. privaatskool) uitgesluit kan word:

Freedom of association entails the right with others to exclude nonconformists. It also includes the right to require those who join the association to conform with its principles and rules. 
Benewens die verpligting wat daar op die leerders geplaas kan word om godsdiensbeoefeningsgeleenthede by te woon, kan die leerders van 'n privaatskool ook gedwing word om die godsdiensklasse by te woon. Regter Dijkstra verwoord dit soos volg

Does this mean that private parochial schools which do not receive State aid may not prescribe obligatory attendance at their morning prayers and confessional religious instruction classes? The answer is negative.

\section{Samevatting}

Op die keper beskou, blyk dit dat verskeie aspekte van die artikels wat in die Suid-Afrikaanse Grondwet betrekking het op godsdiensvryheid, in pas is met volkeregtelike bepalings in die verband. So byvoorbeeld vind 'n mens ook 'n verbreding van die begrip godsdiens na die begrippe soos denke, gewete en geloof in artikel 18 van die Verenigde Nasies se Universele Deklarasie van Menseregte. Dié Deklarasie van die Vernigde Nasies het dan ook erkenning verleen aan die kollektiewe aard van godsdiens en godsdiensbeoefening, die reg tot vrye assosiasie sowel as die openbare uitlewing daarvan.

Weens die godsdienspluralisme in Suid-Afrika is dit essensieel dat leerder en opvoeder 'n reg het op staatsbeskerming van sy geloofsoortuigings. In die lig van die Suid-Afrikaanse Grondwet word die beskermingsrol van die staat nie gekenmerk deur die neutraliteit van skeiding tussen staat en kerk nie, maar eerder deur 'n houding van staatsonpartydigheid. Dit is binne hierdie raamwerk wat leerders van verskillende godsdiensoortuigings ruim geleentheid gegun word om by openbare skole hul reg op godsdiensvryheid uit te leef deur dit individueel of kollektief te bely en te beoefen. Hulle het selfs die reg om byvoorbeeld ' $n$ vereniging vir die uitlewing daarvan by die skool op te rig. In sy rol van onpartydigheid word daar van die staat verwag om toe te sien dat die godsdiensvryheid en -beoefening op 'n billike grondslag, en op 'n vry en vrywillige grondslag sal plaasvind. Ook word daar van die staat verwag om dit deur die daarstelling van reëls te reguleer.

\section{Bibliografie}

CHASKALSON, M., KENTRIDGE, J., KLAAREN, J., MARCUS, G., SPITZ, D. \& WOOLMAN, S 1999. Constitutional law of South Africa. Kenwyn: Juta.

DU PLESSIS, L.M. 1996. An evaluation with particular reference to the bill of rights Orientation, 79(82): 151-674.

DE WAAL, J., CURRIE, I. \& ERASMUS, G 1999 The bill of rights handbook Kenwyn : Juta.

JONKER, W D. 1993 Demokrasie en godsdiens Tydskrif vir Geesteswetenskappe, $33(4)$ 319-327 
LABUSCHAGNE, J.M.T. 1997. Die begrip "godsdiens" in godsdiensvryheid: 'n Bewussynsantropologiese ekskursie na die evolusiekern van die reg. De Jure, 30(1): 118-134

MALHERBE, E.F.J. 1998. Die grondwetlike beskerming van godsdiensvryheid. Tydskrif vir Suid-Afrikaanse Reg, 4:673-701.

RAUTENBACH, I.M., MALHERBE, E.F.J. 1996. Staatsreg Durban : Butterworths

SIZANI, R.K. 1993. The future constitutional process and the church. African Law Review, 4(4):9-12

SMITH, N. 1997. Freedom of religion under the final constitution. The SA Law Journal, (114):217-225

UNDERKUFFLER-FREUD, L.S. 1997. Religious guarantees in a pluralistic society: Values, problems and limits. South African Public Law, 12(1 \& 2):32-52

UNIVERSELE DEKLARASIE VAN MENSEREGTE. 1948 Die Algemene Vergadering van die Verenigde Nasies. New York.

VAN DER WALT, B.J. 1999. Visie op die werklikheid. Potchefstroom : PU vir CHO.

VENTER, F. 1998. The protection of cultural, linguistic and religious rights. Voordrag gelewer op 9 Mei 1998 in Pretoria by die Konferensie oor: "The Constitutional Protection of Multiculturalism".

VORSTER, J.M. 1996. Teologies-etiese perspektiewe op die Grondwet. Woord en Daad, 356:6-7.

WITTE, J. 1993. The South African experiment in religious human rights - what can be learned from the American experience? Journal for Juridical Science, 18(1):127.

\section{Hofsake:}

Aguilar $v$ Felton 473 US 402 (1985)

Everson $v$ Board of Education 330 US 1 (1947).

Kokkinakis v Greece 17 EHRR 397 (1994).

S v Lawrence 1997(4) SA 1176 (CC).

United States $v$ Seeger 380 US 163 at $176(1965)$.

Wisconsin v Yoder 406 US 205(1972).

Wittmann v Deutscher Schulverein, Pretoria 1998 (4) SA 423 (T).

Wette:

Die Grondwet van die Republiek van Suid-Afrika, 108 van 1996. Pretoria : Staatsdrukker

SA Skolewet 84 van 1996. Pretoria : Staatsdrukker.

\section{Kernbegrippe:}

openbare skole

privaatskole

reg tot godsdiensvryheid

\section{Key concepts:}

right to religious freedom

public schools

private schools 